THIS IS A VERSION OF A PAPER THAT HAS BEEN ACCEPTED FOR PUBLICATION IN RESEARCH IN DEVELOPMENTAL DISABILITIES.

The reference of the article is:

Elstner, S., Diefenbacher, A., Kirst, E. \& Vandevelde, S. (accepted - 19th November 2015). A study on the usefulness and reliability of the "Scheme of Appraisal of Emotional

Development" (SAED) for persons with ID, using direct observation in a group-based assessment procedure. Research in Developmental Disabilities. 


\section{A study on the usefulness and reliability of the "Scheme of Appraisal of Emotional Development" (SAED) for persons with ID using direct observation in a group-based assessment procedure}

Elstner $\mathrm{S}^{1}$, Diefenbacher $\mathrm{A}^{1}$, Kirst $\mathrm{E}^{2}$ Vandevelde $\mathrm{S}^{3}$

${ }^{1}$ Department for Psychiatry, Psychotherapy and Psychosomatics, KEH, Berlin

${ }^{2}$ PHIMEA $\Phi$ Methodische und statistische Beratung, Berlin

${ }^{3}$ Ghent University, Department of Special Education, Ghent, Belgium

Dr. Samuel Elstner, MBA (corresponding author)

Berliner Behandlungszentrum für erwachsene Menschen mit geistiger Behinderung und psychischer Erkrankung

Abteilung für Psychiatrie, Psychotherapie und Psychosomatik

Herzbergstr. 79

10365 Berlin

Mail: s.elstner@keh-berlin.de

Phone: ++49 30547249805

Prof. Dr. Albert Diefenbacher MBA

Abteilung für Psychiatrie, Psychotherapie und Psychosomatik

Herzbergstr. 79

10365 Berlin

Mail: a.diefenbacher@keh-berlin.de 
Erik Kirst

PHIMEA Ф Methodische und statistische Beratung

Neue Schönholzerstr. 13

13187 Berlin

info@phimea.de

Stijn Vandevelde

Department of Special Education

Ghent University

H. Dunantlaan 2

B-9000 Gent

Belgium

Mail: stijn.vandevelde@ugent.be 
Keywords:

Intellectual disabilities

Emotional development

SAED

Group evaluation 


\section{Abstract}

Introduction: Whereas instruments for the assessment of intellectual and social abilities are widely available, instruments for the evaluation of emotional development of persons with intellectual disabilities (ID) are rare. The Scheme of Appraisal of Emotional Development (SAED), an internationally used tool developed by Dosen ( $2005 a, b)$, is one of the latter and is based on interviews with caregivers. The present study aims to investigate the internal consistency and interrater-reliability by changing the interview procedure into a direct observation and evaluation approach by a whole team instead of by one expert.

Method: The level of emotional development of 175 patients admitted to a psychiatric inpatient unit specialized in the treatment of adults with ID was evaluated with the SAED by the treatment team after an observation period of up to two weeks. The inter- and intra-raterreliability was assessed by direct observation of the behaviour of an additional 50 patients by two pairs of raters.

Results: The internal consistency of the SAED dimensions, once rated by team approach, is excellent, and the reliability measures show also good statistical results.

Conclusion and implications: The evaluation of the level of emotional development using the SAED by a group-led and/or direct observational procedure show to be a reliable and useful approach. The group-based procedure yields equal results compared with the usual interview guidelines and might lead to an additional training effect within the respective teams. The rater-reliability measures align with those reported in other studies. 


\section{Introduction}

Intellectual disabilities (ID) have been traditionally defined by focusing exclusively on cognitive and social-adaptive limitations. It is only recently that psychological theory and neurobiological research pointed to the interaction of cognitive, emotional and social developmental issues influenced by genetic and environmental factors and their respective interrelations (Bowlby, 1969; LeDoux, 1993; Lemerise \& Arsenio, 2000; Malatesta \& Wilson, 1988; Piaget, 1953; Rosso, Young, Femia, Yurgelun-Todd, 2004). Hence, from the vantage point of the level of emotional development, the perception of ID as an exclusively cognitive impairment has developed into a more comprehensive view, including cognitive, emotional, and social abilities (Greenspan \& Wieder, 1998; Izard, Youngstrom, Fine, Mostrow, Trentacosta, Campell, 2006; Sroufe, 2009; Baurain, Nader-Grosbois, Dionne, 2013).

This multidimensional view can be regarded as a crucial aspect in the evaluation of challenging behaviour and mental health problems in persons with ID, which are quite common as prevalence figures vary from $10 \%$ to about $20 \%$ for challenging behaviour (Emerson et al., 2001; Lowe 2007; Lundqvist 2013). The risk for developing challenging behaviour is estimated to be three to five times higher for people with ID as compared to the general population (Emerson \& Einfeld 2011). Psychiatric disorders have been identified in $4 \%$ to over $50 \%$ of persons with ID, depending on whether challenging behaviour is incorporated (Whitaker \& Read, 2006 cited in Allen et al., 2007); even higher prevalence figures have been published with regard to children and adolescents (Barron et al., 2013). Some researchers have shown that the emotional development of clients and/or aspects relating to their ecological system may play a pivotal role in the development of problem behaviour, next to somatic or psychiatric issues. Therefore, an integrative approach, combining pedagogical, psychological, pharmaceutical, and social treatment and support methods is warranted (Dosen, 2007). From this point of view, it might be relevant in terms of an efficient therapeutic process to evaluate the level of development in different dimensions, including cognitive functions, social-adaptive behaviour, and emotional abilities (La Malfa, 2009; Matson, 2009a,b; Totsika, 2010; Sappok, 2014).

Whereas instruments for the assessment of intellectual-cognitive and social abilities are widely available (Balboni, Hatton, Limb, 2014; Kaufman \& McLean, 1986; Lemerise \& Arsenio, 2000; Rabin, Barr, Burton, 2005; Sparrow, Balla, Cincchetti, 1984; Wechsler, 1997), instruments for the assessment of the emotional level of people with ID hardly can be found (Bax, 2002). Yet, knowledge about emotional development is as important as knowledge 
about other dimensions, such as intelligence, because it may help to explain the underlying meaning of a person's behavior (Vandevelde et al., 2015). Therefore, it is important to have "objective" (or at least intersubjective) measures of emotional development, especially when self-report is not adequate or suitable. Instruments available internationally include the Scheme of Appraisal of Emotional Development (SAED) (Dosen, 2005a, 2005b; La Malfa, Lassi, Bertelli, Albertini, Dosen, 2009); the Scale for the Assessment of the Social-Emotional Developmental Age Level (SEDAL); an English version of the Dutch ESSEON (Hoekman, Moederma, Otten, Gielen, 2004); the Functional Emotional Assessment Scale (FEAS) (Greenspan, DeGangi, Wieder, 2014); Frankish's tool of measuring the emotional development of persons with ID (Frankish, 2013); and the Infant-Toddler Social and Emotional Assessment (ITSEA) (Carter, Briggs-Gowan, 2000). Most of these instruments have been psychometrically evaluated with regard to internal consistency and convergent validity (investigating correlations with other scales measuring the same or a related concept). The results indicate that these instruments generally show good convergence to other scales, display good internal consistency and are convenient to administer (Carter, Briggs-Gowan, Jones, Little, 2003; Hoekman et al., 2004; La Malfa et al., 2009).

In this study, the SAED has been used, as it emphasizes the role of emotional development in understanding behaviour and behavioural problems in children, adolescents, and adults with ID (Dosen, 2005a, 2005b). The SAED sheds light on basic emotional needs, personality traits and behaviour features; it differs from the other above-mentioned instruments as it specifically differentiates emotional development from the social and cognitive development (Vandevelde et al., 2015). Applying the SAED helps to understand psychological developmental aspects. The emotional development is related to a scheme of developmental steps in the first 12 years of life, which are appropriate for both children and adults, as the emotional development typically stagnates in persons with ID (de Schipper \& Schuengel 2010; Sappok 2014), although qualitative changes within the different domains may still be observed. Moreover, quite often a discrepancy is observed between a higher cognitive and a lower emotional development (Dosen, 2005a). The scheme divides the time span of 12 years into 5 phases of emotional development. Additionally, the SAED defines 10 dimensions ("psycho-social aspects") and lists emotional and behavioural characteristics typical for each developmental stage (Table 1). The evaluation of emotional development is typically based on interviews with caregivers or social network members, carried out by interviewers experienced in developmental psychology and psychiatry and trained in administering the SAED. This means that the original version of the SAED was developed to be used as an indirect evaluation tool. The estimated time for the interview is about 20 to 30 minutes 
(Sappok, Budzies, Dziobek, Bölte, Dosen, Diefenbacher, 2014), not including the time of transferring the results to the members of a treatment team, which cannot be exactly specified. In the developer's view, the SAED should be regarded as a practice-based tool for evaluating the emotional development with a high potential for clinical relevance in the treatment planning of problem behaviour which is not (or partially) caused by somatic and/or psychiatric reasons (see, e.g., Dosen, 2008). When using the SAED and its underlying theoretical framework on emotional development, support workers are obliged to go beyond 'mere' symptom reduction (e.g., by using medication and/or behaviour therapy as standalone approaches) in treatment and support planning and implementation, as it highlights the importance of adapting the environment and context to the basic needs of clients (Vandevelde et al., 2015).

The current study pursues another way to advance the original SAED further in two directions. (1) The first direction was to avoid a possible interviewer bias. We changed the method of data acquisition to elicit the caregivers' opinions from an expert interview to a direct observational approach towards the patient's behaviour, i.e., the person who provides the information and the person who in fact rates the behaviour are the same. (2) Secondly, we aimed at developing a procedure which is easy and effective to handle in the routine care of an inpatient unit for adults with ID and co-occurring psychiatric and/or behaviour disorders. Therefore, it was decided that the members of the therapeutic and nursing team of the wards should discuss their impressions of the patient's behaviour. This approach replaces the conventional procedure where an interviewer rates the patient's emotional developmental level by information provided by other informants (e.g., natural caregivers) and passes on the reviewed information afterwards to inform the rest of the therapeutic team. That conventional procedure disregards the potential of the participation of the whole team in the discussion about the patient's behaviour. On the other hand, the natural caregivers do know the patient in their home situation for a long time already. At first sight, it seems to be self-evident that these caregivers know the patient better (which is mostly the case, as we are convinced that natural caregivers, such as parents, are experts with regard to their child or relative) than a clinical staff member in an unfamiliar hospital. Yet, a temporary stay in a residential facility may offer an opportunity for the patients to be seen with "neutral and complementary eyes" and for patients to show their abilities in the challenges of a new setting and a group of other, unknown people. 
Further, during the team discussion a common understanding can develop which prevents the growth of negative feelings towards the patient (Bailey, Hatton, Limb, 2006; Hastings \& Brown, 2001). This team-based approach can contribute to a change of attitude towards the patient (Singh, Singh, Sabaawi, Myers, Wahler, 2006). Eventually, this could result in a treatment plan with more thoughtful interpersonal collaboration between team and patient (Narashimham, Eisen, Mahoney, Acerra, Rosen, 2006). These are good arguments for the assertion that involving the team in the scoring process could potentially lead to more positive effects. However, we have not yet analysed whether the reliability of the results of such a team-based, direct observation approach is equivalent to the traditional interviewbased assessment (La Malfa et al., 2009; Vandevelde et al., 2015).

The research questions of our paper are two-fold: (1) Does the level of emotional- and the level of cognitive development differ? (2) What is the internal consistency and the intra- and inter-rater-reliability of the team-based approach? In the discussion section, the results of the team-based direct observational approach set forth in this article, will be compared with findings of previous studies that reported on the reliability of the SAED or its revised version, the SED-R (Claes \& Verduyn, 2012; Vandevelde et al., 2015).

\section{Methods}

\subsection{Setting and patient sample}

The specialized treatment centre for adult inpatients with ID and psychiatric disorders of the KEH General Hospital in Berlin has two wards. Patients of the wards differ in their ability of verbal communication and the level of intellectual impairment. Data were collected prospectively in the order of the patients' consecutive admission from October 2013 to September 2014, for which a SAED evaluation was applied. There was no randomisation based on gender or level of ID as the study was not focused on comparing groups. The assessments were part of the routine procedures and were documented in the hospital's regular patient-database. The names of the participating patients were anonymized before statistical processing. This procedure is in accordance with the prevailing rules on ethics and privacy in Germany (Senate Department of Justice, 2011).

For each patient, data on sex, age, emotional development, and level of intellectual disability were registered. 
The level of intellectual functioning was assessed either with the German version (WIE) of the Wechsler Adult Intelligence Scale (WAIS-II), the Kaufmann-ABC for Children, the Coloured Progressive Matrices (CPM) by Raven, or the Snijders-Oomen-Non-VerbalIntelligence-Test before or during inpatient treatment. Where standardized tests could not be used due to a patient's low level of functioning, the Disability Assessment Scale (DAS) was applied. The DAS shows a good correlation with the level of intellectual functioning (Holmes, Shah, Wing, 1982; Meins \& Süssmann, 1993) except for patients with additional physical motoric handicaps which hampered them in performing everyday activities, e.g., tying their shoe-laces. For that reason, the latter patients were excluded from the study, after a thorough physical examination by an experienced medical doctor, although it should be acknowledged that physical disabilities are frequent in this patient group. The DAS was assessed by members of the nursing teams. The IQ cut-off points were in accordance with the ICD-10 definitions (profound/severe: up to 35, moderate: 35-50, mild: 50-70).

\subsection{Procedure}

During the patients' stay, the SAED assessment had started after a minimum observation period of two weeks following the patients' admission in order to allow the patient to familiarize himself or herself with the treatment team. The assessment was only performed in periods during which the patients showed no or negligible acute psychiatric or somatic symptoms, which were clinically assessed by experienced psychiatrists and physicians. The observations lasted from the admittance of the patient until psychopathological improvement in the case of psychiatric illness; until elimination of the cause in case of somatic reasons; and after a minimum of two weeks in the case of systemic caused behaviour in order to permit the treatment staff to get to know the patient well enough.

In the aspects of evaluation of the effects on the SAED by changing the previous interview mode into a direct observation and team-based mode, we had to go a two-way strategy (Figure 1):

(1) Internal-consistency of the SAED - The change from one person- to the team-based assessment:

The SAED was assessed by all members of the therapeutic team of each ward, i.e., 2 psychiatrists, 1 psychologist, 3 to 4 members of the nursing staff, 1 educational therapist, and 2 to 3 occupational therapists. The whole team was trained in the integrative model 
developed by Dosen (2007) and has extensive experience in working with the SAED since 2012.

(2) Rater-reliability - The change from indirect to direct evaluation mode:

In order to assess the intra- and the inter-rater-reliability, two persons of each ward with the same professional background who had (1) extensive experience in administering the SAED, and who had (2) high contact rates with patients, were selected to form a rating pair. This resulted in two pairs, one per ward, with each pair consisting of two members of the nursing teams. For Intra-Rater-Reliability the SAED-administration was conducted by one part of the rater-pair of each ward (pair 1 or pair 2), and was repeated by the same part of the same rating pair at least 1 week after the first administration. For assessing the inter-raterreliability, both raters of the same pair (pair 1 or 2) applied the SAED of the same patient within 3 days.

As the raters of the rater-reliability-teams were also members of the ward teams, the SAED group-based evaluation was carried out with 175 patients. The SAED intra-rater-reliabilityevaluation was carried out with 50 patients different from the first ones. To evaluate the interrater-reliability between the whole teams of the ward we would have had to change the teams and wards, which would have been too disturbing for the patients. Therefore, it was decided to refrain from that approach for ethical reasons. Moreover, due to organisational reasons concerning shift work, holidays, or acute illness the same team composition proved to be difficult to guarantee. Therefore, we preferred to evaluate the intra-rater-reliability by the ward-pairs. These pairs evaluated the emotional development level of 50 patients altogether (pair 1: 30 patients, pair 2: 20 patients) in the daily routine by direct observation instead of the traditional interview (Figure 1).

\subsection{Statistical analysis}

The analysis methods are described in relation to the three research questions mentioned above:

(1) After using descriptive statistics to characterise the sample, different statistical methods were applied to examine the relationships as well as differences between individual characteristics, especially the relation between cognitive impairment and emotional development. The variables that were included in the analyses were sex, age, diagnosis, 
level of cognitive impairment, and the total SAED score. In order to account for varying scales of the variables (e.g., the nominal, ordinal and interval scale), different statistical techniques were used. These included the Pearson bi-serial correlation $(r)$ for sex as a dichotomous variable and age as a metric one, the Spearman correlation $(\rho)$ for the dichotomous variable (sex), and ordinal variables (cognitive impairment, level of emotional development by SAED), the Chi-Square-Test (sex and diagnoses), and the Kruskal-WallisTest. The latter was used to investigate differences in age between patients with different diagnoses.

(2) To assess the internal consistency of the 10 SAED dimensions, Cronbach's coefficient $\alpha$ (Cronbach, 1951) was calculated as a measure of reliability. Furthermore, to obtain a more detailed view on the dimensions' relations, an inter-correlation matrix was generated to show all correlations between the dimensions. Again, the Spearman correlation was chosen as the appropriate analysis due to the ordinal scale data. The data of our observation-teamapproach will be compared with data from the literature, which were mostly based on the conventional interview procedure (La Malfa et al., 2009; Vandevelde et al., 2015).

(3) To assess the intra- and inter-rater-reliability of the rank-ordered data, the coefficient weighted kappa (Cohen, 1968; Fleiss, Levin, Paik, 2003) was calculated. According to Altman (1991), the following thresholds were used to interpret weighted kappa (Table 1): weighted kappa form 0.00 to 0.20 stands for a poor strength of agreement, $0.21-0.40$ for a fair, $0.41-0.60$ for a moderate, $0.61-0.80$ for a good and $0.81-1.00$ for a very good strength of agreement.

\section{Results}

3.1 Relations between patients' characteristics and emotional development

In total, 175 patients (99 male adults and 76 female adults) were included in the teamevaluation sample, and 50 patients were included in the rater-reliability sample. In Table 2 , the demographic and clinical data of the study samples and the relations per sample are listed. A statistically significant, moderate correlation between the level of cognitive impairment and emotional development was found $(\rho=0.52 ; p<.001 / \rho=0.668 ; p<.001)$. For the female and male patients we found differences in the occurrence of diagnoses $(p=.005)$ in the team-evaluation-sample, which goes along with the common knowledge of sex difference for psychiatric disorders (Table 3). 
There was no significant evidence of a relation between sex and age $(p=.95 ; p=.592)$, sex and the level of cognitive impairment $(p=.81 ; p=.694)$, sex and SAED-score $(p=.27 ; p=.558)$ and age and the level of cognitive impairment $(p=.12 ; p=.198)$ in both samples. Furthermore, no evidence was found for differences in age between patients with varying diagnoses $(p=.63 ; p=.398)$. A small negative correlation ( $\rho=-.16, p=.034 ;=-152 ; p=.292$ ) was found between age and SAED-score as a rather small effect in both samples, but without statistical significance in the intra- and inter-rater-reliability-sample $(p=.292)$.

\subsection{SAED internal consistency for the observational procedure}

The Cronbach's alpha coefficient was 0.94 , and therefore the internal consistency is excellent. Except for "objective permanence" (dimension 4), every other dimension highly correlated with the total SAED score (Spearman's $\rho>0.7, p<.01$ ). Additionally, all dimensions were positively correlated (Spearman's $\rho$ between 0.4 and $0.8, p<.01$ ).

\subsection{Intra-and inter-rater-reliability (weighted kappa)}

Table 5 shows the coefficients for intra- and inter-rater-reliability, ranging from low values, or slightly more than .3 for dimension 4 (objective permanence) to a highly weighted kappa over .8 for dimension 7 (handling with material objects).

The results for the intra-rater-reliability showed highly weighted kappa scores over 0.7 in 7 of 10 dimensions, plus for the total SEAD score. In our sample, the lowest kappa score was found for dimension 10 (affect regulation), representing a moderate agreement.

In addition, the inter-rater-reliability objective permanency showed the lowest score. The inter-rater-reliability is - in general - lower than the intra-rater-reliability.

\section{Discussion}

To the best of our knowledge, this is the first study that evaluates the internal consistency and the intra- and inter-rater-reliability of the SAED administered by a team-led and/or direct observation approach, which is different from the conventional single-expert interview-based procedure. There is only one study in which the SAED was assessed using a combination of a single interview and group-based approach (Sappok, Budczies, Bölte, Dziobek, Dosen, Diefenbacher, 2013). 
We found significant differences between diagnosis and sex, which aligns with other studies in the psychiatric field (Kessler,, 2007; Wittchen et al., 2011; Reneres et al., 2014). A moderate correlation between the level of cognitive impairment and the level of the emotional development could be confirmed for the group of physically non-handicapped patients with ID. This limitation should be mentioned here. The exclusion of physically handicapped people, who would have reached lower ratings in the DAS, was done in order to avoid a possible impairment of the correspondence of the DAS with the cognitive impairment levels. In our opinion the exclusion of that subgroup is negligible considering our study's aim concerning the setting change from interview- to observation-approach. We interpret that moderate finding as evidence for a parallel development of these two dimensions. Yet, in some cases differences were found based on the theoretical framework of emotional development (see, e.g., Dosen, 2005a); we believe that these differences contribute to the development and prolongation of problem behaviour. Therefore, we think it is crucial that both the cognitive- and the emotional developmental levels are assessed in people with ID. No significant correlations were found for "age", "sex" and "IQ". These results are in line with findings in the international literature (Izard et al., 2006; Mayer, Roberts, Barsade, 2008; Sappok et al., 2014; Matson 2009a,b; Totsika 2010).

With a Cronbach's $\alpha$ of 0.94 , the internal consistency of the SAED, as scored by the team, can be interpreted as very high. This finding is similar to the results of other studies carried out by La Malfa and his colleagues (2009) who used the Italian version of the SAED (.96), and by Vandevelde and his colleagues (2015) using the revised Dutch version of the SED-R (.95). These studies used the conventional interview-based procedure. Based on our results, it seems that a team-based assessment does not negatively influence the internal consistency of the scale.

Divergent from the design in which we used the setting of a team, the intra- and inter-raterreliability was based on scores given by single team members. However, this study still supports the idea of gaining the data through team members' direct observation. Intra-raterreliability seems to be quite good, whereas the inter-rater-reliability shows lower results; this seems logical and is in line with our expectations. In our opinion, the lower inter-rater-scores in comparison with the intra-rater-scores can be explained by the fact that the informant and the interviewer were actually the same person; this could have prevented an objective rating. The correlations achieved in our study are slightly higher than the figures using the SED-R, 
based on interviews with caregivers (Vandevelde et al., 2015). This supports the value of a team-based approach, as divergent ratings by different team members may lead to a more "correct" (or at least more inter-subjective) figure.

\section{Team evaluation}

What are the advantages of our approach? First, there may be a time saving effect. In a previous study, we were able to show the effectiveness of a team-based approach of the SAED; after only 4 weeks of training, a psychiatric team learned to use this instrument and was able to perform reliably a SAED-rating within about 11 minutes (Elstner, Diefenbacher, Heinrich, 2015). This reduces the time for assessment to at least half the time used for the traditional assessment (Sappok et al., 2014). However, as a team with more than three members is involved in the scoring process, this might mitigate the time saving effect. Keeping in mind the additional time needed for information transfer to team members in the interviewer evaluation setting, a time saving effect with the team approach process could be assumed, however. On the other hand, it might well be that the involvement of a team as a whole could lead to a better performance during treatment due to better knowledge of the patient. Moreover, this could consequently lead to better health care (Narashimham et al., 2006). The more team members are engaged in trying to understand the patient's behaviour and his or her actual emotional needs, the easier daily routine care might be performed, possibly resulting in less stressful interactions between caregivers and patients (Bailey et al., 2006; Hastings \& Brown, 2001). Furthermore, the whole team develops a common ground in an integrative diagnosis. The positive effect of involving a whole team of caregivers into the treatment of a patient has already been described in other studies (Charlot, 2003; Dosen, 2007; Elstner, Feuerherd, Vogel, Diefenbacher, 2012; Greenspan \& Wieder, 1998; Sturmey, 1999). We may suppose that a caregiver team in residential homes, who knows its patients better and longer than a clinical team, would produce an even better estimation that is closer to reality. Furthermore, the fact that the whole team is involved could be considered to be time-efficient as the team members discuss "in team" and by doing so already start the treatment process collectively (the assessment could - in this case - be considered to be an integrated part of support and treatment planning and implementation).

Hence, our study underscores that a team-orientated approach for the SAED scoring process may have some advantages with regard to support planning and delivery of patient care. At the same time, this approach seems to produce comparable or even slightly better results with regard to internal consistency and reliability than the usual approach. 
Some limitations of our study should be noted. First, we have to take into account that comparisons are made between studies using the SAED and the SED-R, the latter being a revised version of the original SAED with slight modifications. Yet, as the administration procedure of both instruments is alike, we have also incorporated figures based on the SEDR. Second, the scoring was carried out by two different teams in only one treatment centre, which means that we cannot exclude a team- and institution-bias. Third, the study design was divided over two patient samples because of the above-mentioned problems in evaluating the intra- and inter-rater-reliability with all team members. We tried to reduce that problem by choosing experienced staff members with a similar working background. Furthermore, the patient sample was clinically selected, as only patients with acute behavioural problems come to the centre. A psychiatric disorder per se represents an important possible confounding variable. However, by including only psychiatrically improved patients we tried to control the effect of this variable. Lastly, the assessment of psychiatric disorders was based only on the clinical judgement of psychiatrists (yet, both have extensive experience in the field of ID). In this respect, it would be relevant to tackle these limitations in future research. It would be particularly interesting, for example, to study the relationship between SAED-levels and specific psychiatric diagnoses in order to develop possible profiles which could be used for support and treatment planning and implementation.

\section{Conclusion}

The evaluation of the level of emotional development using the SAED by a group-led and/or direct observation procedure has proven to be a reliable and useful approach.

This paper intended to investigate this scale for inpatient use in acute psychiatric hospitals. Instead of interviewing caregivers, the treatment team carried out the assessment through direct observation. The internal consistency of the SAED was high, and the reliability measures corresponded to those reported in other studies using the conventional approach.

We conclude that the SAED is a feasible instrument for the evaluation of emotional development in people with ID also when the whole treatment team-assessment approach is used. Especially in patients with problem behaviour, for whom psychiatric or somatic disorders as possible causing factors cannot be retained, the SAED can support the creation of an integrative treatment or support plan. The alternative procedure described in this paper yields equal results as compared with the usual interview guidelines and, in addition, might 
lead to a training effect within teams applying this approach. The satisfying reliability variables suggest that in case of team treatment the team direct observation approach may be at least as much and possibly more effective than the one based on the interview-format.

\section{Acknowledgements}

We thank our staff for performing the assessments, esp. Nicole Gutzoff, Tamara Klockmann, Christine Stopfkuchen and Christoph Büdding for the interrater-reliability-ratings, and Sabine Zepperitz and Christian Feuerherd for data entry.

\section{References}

Allen, D., Lowe, K., Matthews, H. and Anness, V. (2012). Screening for Psychiatric Disorders in a Total Population of Adults with Intellectual Disability and Challenging Behaviour Using the PAS-ADD Checklist. Journal of Applied Research in Intellectual Disabilities, 25, 342-349.

Barron, D. A., Molosankwe, I., Romeo, R. and Hassiotis, A. (2013).Urban adolescents with intellectual disability and challenging behaviour: costs and characteristics during transition to adult services. Health \& Social Care in the Community, 21, 283-292.

Altmann, D.G. (1991). Practical statistics for medical research. London: Chapman and Hall 
Bailey, B. A., D.J., H., Hatton, C., Limb, K. (2006). The response to challenging behaviour by care staff: emotional responses, attributions of cause and observations of practice. Journal of Intellectual Disability Research, 50, 199-211.

Balboni, G., Tasse, M. J., Schalock, R. L., Borthwick-Duffy, S. A., Thissen, D., Widaman, K. F., Zhang, D., Navas, P. (2014). The Diagnostic Adaptive Behavior Scale: evaluating its diagnostic sensitivity and specificity. Research in Developmental Disabilities, 35, 2884-2893.

Baurain, C., Nader-Grosbois, N., Dionne, C. (2013). Socio-emotional regulation in children with intellectual disability and typically developing children, and teachers' perceptions of their social adjustment. Research in Developmental Disabilities, 34, 2774-87.

Bax, M. C. O. (2002). Neurology or psychiatry? Developmental Medicine and Child Neurology, 44, 291.

Bowlby, B. (1969). Attachment and loss. London: Hogart Press.

Carter, A. S., Briggs-Gowan, M. J. (2000). Infant-Toddler Social and Emotional Assessment (ITSEA). Manual (Yale Unive.). New Haven, CT.

Carter, A. S., Briggs-Gowan, M. J., Jones, S. M., Little, T. D. (2003). The Infant-Toddler Social and Emotional Assessment: Factor structure, reliability, and validity. Journal of Abnormal Child Psychology, 51, 495-514.

Charlot, L. R. (2003). Mission impossible? Developing an accurate classification of psychiatric disorders for individuals with developmental disabilities. Mental Health Aspects of Developmental Disabilities, 6, 26-35.

Claes, L. ,Verduyn, A. (2012).Schaal voor Emotionele ontwikkeling bij mensen met een verstandelijke beperking - Revised. Antwerpen, Apeldoorn: Garant Uitgevers nv.

Cohen, J. (1968). Weighted kappa: Nominal scale agreement with provision for scaled disagreement or partial credit. Psychological Bulletin, 4, 213-220.

Cronbach, L. J. (1951). Coefficient alpha and the internal structure of tests. Psychometrika, 16, 297-334.

De Schipper J, Schuengel C (2010). Attachment behaviour towards support staff in young people with intellectual disabilities: associations with challenging behaviour. Journal of intellectual disability research. 54, 584-596 
Dosen, A. (2005a). Applying the developmental perspective in the psychiatric assessment and diagnosis of persons with intellectual disability: part I-assessment. Journal of Intellectual Disability Research, 49, 1-8.

Dosen, A. (2005b). Applying the developmental perspective in the psychiatric assessment and diagnosis of persons with intellectual disability: part II-diagnosis. Journal of Intellectual Disability Research, 49, 9-15.

Dosen, A. (2007). Integrative treatment in persons with intellectual disability and mental health problems. Journal of intellectual disability research, $51,66-74$.

Dosen, A. (2008). Psychische stoornissen, gedragsproblemen en verstandelijke handicap. Een integratieve benadering bij kinderen en volwassenen [Psychiatric disorders, behaviour problems and intellectual disability. An integrative approach in children and adolescents]. Assen: Koninklijke Van Gorcum.

Elstner, S., Diefenbacher, A., Heinrich, M. (2015). Establishing a team-scoring model for socio-emotional development of patients with intellectual disabilities. Psychiatrische Praxis, $42,35-41$.

Elstner, S., Feuerherd, C., Vogel, M., Diefenbacher, A. (2012). Sagen Sie, warum bin ich immer so schnell wütend? - Konzept der mehrdimensionalen integrativen Behandlung on der psychiatrischen Versorgung von Menschen mit geistiger Behinderung. Medizin für Menschen mit geistiger Behinderung, 9, 95-101.

Emerson, E., Kiernan, C., Alborz, A., Reeves, D., Mason, H., Swarbrick, R., Mason, L., Hatton, C. (2001). The prevalence of challenging behaviors: a total population study. Research in Developmental Disabilities, 22, 77-93.

Emerson E., Einfeld S.L. (2011). Challenging behaviour. 3rd Edition, Cambridge: University press.

Fleiss, J.L., Levin, B., Paik M.C. (2003). Statistical methods for rates and proportions. Hoboken: John Wiley \& Sons

Frankish, P. (2013). Measuring the emotional development of adults with ID. Advances in Mental Health and Intellectual Disabilities, 7, 272-276.

Greenspan, S., DeGangi, G., Wieder, S. (2014). The Functional emotional assessment scale (FEAS) for infant and early childhood. Clinical and research applications. Bethesda.

Greenspan, S. J., Wieder, S. (1998). The Child with Special Needs. Reading, Massachusetts: Perseus Books. 
Hastings, R. P., Brown, T. (2001). Behavioural knowledge, causal beliefs and self-efficacy as predictors. Journal of Intellectual Disability Research, 46, 144-150.

Hoekman, J., Moederma, A., Otten, B. R., Gielen, J. (2004). Diagnosing socioal-emotional development: the SEDAL-scale (abstract). Journal of Intellectual Disability Research, 48, 5.

Holmes, N., Shah, A., Wing, L. (1982). The Disability Assessment Schedule: a brief screening device for use with the mentally retarded. Psychological Medicine, 12, 879-90.

Izard, C. E., Youngstrom, E. A., Fine, S. E., Mostrow, A. J., Trentacosta, C. J., Campell, J. (2006). Emotions and developmental psychopathology. In C. D. Cicchetti D (Ed.), Developmental psychopathology (pp. 244-292). New York: Wiley.

Kaufman, A. S., McLean, J. E. (1986). K-ABC/ WISC-R factor analyses for a learning disabled population. Journal of Learning Disabilities, 19, 145-153.

Kessler R.C. (2007). The Global Burden of Anxiety and Mood Disorders: Putting the European Study of the Epidemiology of Mental Disorders (ESEMeD) Findings into Perspective. J Clin Psychiatry, 68, 10-19

La Malfa, G., Lassi, S., Bertelli, M., Albertini, G., Dosen, A. (2009). Emotional development and adaptive abilities in adults with intellectual disability. A correlation study between the Scheme of Appraisal of Emotional Development (SAED) and Vineland Adaptive Behavior Scale (VABS). Research in Developmental Disabilities, 30, 1406-1412.

Le Doux, J. E. (1993). Emotional Network in the brain. In H. J. Lewis M (Ed.), Handbook of emotions (pp. 109-118). New York: Guilford.

Lemerise, E. A., Arsenio, W. F. (2000). An integrated model of emotion processes and cognition in social information processing. Child Development, 71, 107-18.

Lowe K, Allen E, Jones E, Brophy K, Lames W (2007). Challenging behaviours: prevalence and topographies. Journal of intellectual disability research, 51, 625-636

Lundqvist $L$ (2013). Prevalence and risk markers of behavior problems among adults with intellectual disabilities: a total population study in Örebro County, Sweden. Research in Developmental Disabilities; 234, 1346-1356.

Malatesta, C. Z., Wilson, A. (1988). Emotion cognition interaction in personality development: a discrete emotions, functionalist analysis. The British Journal of Social Psychology, 27, 91112. 
Mayer, J. D., Roberts, R. D., Barsade, S. G. (2008). Human abilities: emotional intelligence. Annual Review of Psychology, 59, 507-536.

Meins, W., Süssmann, D. (1993). Evaluation of an adaptive behaviour classification for mentally retarded adults. Social Psychiatry and Psychiatric Epidemiology, 28, 201-5.

Narashimham, M., Eisen, L. A., Mahoney, C. D., Acerra, F. L., Rosen, M. J. (2006). Improving nurse-physician communication and satisfaction in the intensive care unit with a daily goals worksheet. American Journal of Critical Care, 15, 217-222.

Piaget, J. (1953). The child's construction of reality. London: Routledge \& Kegan Paul.

Rabin L.A., Barr W.B., Burton L. A. (2005). Assessment practices of clinical neuropsychologists in the Unitied States and Canada: a survey of INS, NAN and APA Division 40 members. Archives of Clinical Neuropsychology, 20, 33-65

Reneses B., Garrido S., Navalon A., Martin O., Ramos I., Fuentes M., Moreno J., Lopez-Ibor J.J. (2015). Psychiazry morbididty and predisposing factors in a primary care population in Madrid. Int J Soc Psychiatry, 61, 275-286

Rosso, I. M., Young, A. D., Femia, L. A., Yurgelun-Todd, D. A. (2004). Cognitive and emotional components of frontal lobe functioning in childhood and adolescence. Annals of the New York Academy of Sciences, 1021, 355-62

Sappok, T., Budczies, J., Bölte, S., Dziobek, I., Dosen, A., Diefenbacher, A. (2013). Emotional development in adults with autism and intellectual disabilities: a retrospective, clinical analysis. PloS One, 8, e74036

Sappok, T., Budczies, J., Dziobek, I., Bölte, S., Dosen, A., Diefenbacher, A. (2014). The missing link: delayed emotional development predicts challenging behavior in adults with intellectual disability. Journal of Autism and Developmental Disorders, 44, 786-800

Senate Department of Justice (Senatsverwaltung für Justiz). (2011). § 25: Datenschutz bei Forschungsvorhaben. Gesetz- und Verordnungsblatt für Berlin, 67, 488.

Singh, N. N., Singh, S. D., Sabaawi, M., Myers, R. E., Wahler, R. G. (2006). Enhancing treatment team process through mindfulness-based mentoring in an inpatient psychiatric hospital. Behavioral Modification, 30, 423-441.

Sparrow, S., Balla, D., Cincchetti, D. (1984). Vineland Adaptive Behaviour Scale. Circle P'Pines, Minnesota: American Guidance Service. 
Sroufe, L. A. (2009). The Concept of Development in Developmental Psychopathology. Child Development Perspectives, 3, 178-183.

Sturmey, P. (1999). Classification: concepts, progress and future. In N. Bouras (Ed.), Psychiatry and behavioural Disorders in Developmental and Mental Retardation (pp. 3-17). Cambridge: Cambridge University Press.

Totsika V, Felce D, Kerr M, Hastings RP (2010). Behavior problems, psychiatric symptoms, and quality of life for older adults with intellectual disability with and without autism. J Autism Dev Disord, 40, 1171-1178

Vandevelde, S., Morisse, F., Došen, A., Poppe, L., Jonckheere, B., van Hove, G., Maes B., van Loon J., Claes, C. (2015). The Scale for Emotional Development-Revised (SED-R) for persons with intellectual disabilities and mental health problems: Development, description, and reliability. International Journal of Developmental Disabilities., in press.

Wechsler, D. (1997). Wechsler Adult Intelligence Scale (3rd ed.). San Antonio, TX: Psychological Corporation

Whitaker S., Read S. (2006). The prevalence of psychiatric disorders among people with intellectual disabilities: an analysis of the literature. Journal of Applied Research in Intellectual Disabilities, 19, 330-345

Wittchen H.U., Jacobi F., Rehm J., Gustavsson A., Svensson M., Jönsson B., Olesen J., Allgulander C., Alonso J., Faravelli C., Fratiglioni L., Jennum P., Lieb R., Maerker A., van Os J., Preisig M., Salvador-Carulla L., Simon R., Steinhausen H. C. (2011). The size and burden of mental disorders and other disorders of the brain in Europe 2010. Eur Neuropsychopharmacol, 21, 655-679 
Table 1: The Scheme of Appraisal of Emotional Development (SAED) (according to Dosen, 2005a,b)

\section{Psycho-social aspects}

1. How he deals with his own body

2. Interaction with caregivers

3. Experience of self

4. Object permanency

5. Anxiety

6. Interaction with peers

7. Handling with material objects

8. Verbal communication

9. Affect differentiation

10. Aggression regulation

\section{Phases of emotional development}

Phase 1: Adaptation (0-6 month)

Phase 2: Socialization (6-18 months)

Phase 3: Individuation (18-36 months)

Phase 4: Identification (3-7 years)

Phase 5: Reality awareness (7-12 years) 
Table 2: Patient sample (sex, age, cognitive impairment, psychiatric diagnoses, and developmental level)

\section{Sample 1: Team evaluation $(n=175)$}

\begin{tabular}{|c|c|c|c|c|c|c|c|c|c|}
\hline \multirow[t]{2}{*}{$\operatorname{sex}$} & \multicolumn{3}{|l|}{ male } & \multicolumn{2}{|l|}{ female } & \multicolumn{4}{|l|}{ total } \\
\hline & \multicolumn{3}{|c|}{$99(56.6 \%)$} & \multicolumn{2}{|c|}{$76(43.4 \%)$} & \multicolumn{4}{|c|}{$175(100 \%)$} \\
\hline age & \multicolumn{3}{|c|}{$35.3(\mathrm{sd}=11.5)$} & \multicolumn{2}{|c|}{$35.5(\mathrm{sd}=11.4)$} & \multicolumn{4}{|c|}{$35.4(\mathrm{sd}=11.4)$} \\
\hline \multirow[t]{2}{*}{ cognitive impairment } & mci & moci & sci & pci & $\mathrm{mm}$ & \multicolumn{4}{|l|}{ total } \\
\hline & $42(24 \%)$ & $\begin{array}{l}80 \\
(45.7 \%)\end{array}$ & $\begin{array}{l}44 \\
(25.1 \%)\end{array}$ & $\begin{array}{l}3 \\
(1.7 \%)\end{array}$ & $\begin{array}{l}6 \\
(3.4 \%)\end{array}$ & \multicolumn{4}{|l|}{$\begin{array}{l}175 \\
(100 \%)\end{array}$} \\
\hline \multirow[t]{2}{*}{ diagnoses } & Fo & F2 & F3 & F4 & F6 & ADHD & Autism & ns & total \\
\hline & $\begin{array}{l}6 \\
(3.4 \%)\end{array}$ & $36(20.6)$ & $69(39.4)$ & $\begin{array}{l}24 \\
(13.7 \%)\end{array}$ & $\begin{array}{l}4 \\
(2.3 \%)\end{array}$ & $1(0.6 \%)$ & $\begin{array}{l}18 \\
(10.3 \%)\end{array}$ & $\begin{array}{l}17 \\
(9.7 \%)\end{array}$ & $\begin{array}{l}175 \\
(100 \%)\end{array}$ \\
\hline developmental level & fa & fs & fin & fid & $\mathrm{r}$ & \multicolumn{4}{|l|}{ total } \\
\hline acoording SAED & $\begin{array}{l}18 \\
(10.3 \%)\end{array}$ & $\begin{array}{l}19 \\
(10.9 \%)\end{array}$ & $\begin{array}{l}55 \\
(31.4 \%)\end{array}$ & $54(30.9)$ & $\begin{array}{l}29 \\
(16.6)\end{array}$ & \multicolumn{4}{|l|}{$\begin{array}{l}175 \\
(100 \%)\end{array}$} \\
\hline
\end{tabular}

Sample 2: Intra- and inter-rater-pairs-evaluation $(n=50)$

\begin{tabular}{|c|c|c|c|c|c|c|c|c|c|}
\hline \multirow[t]{2}{*}{ sex } & \multicolumn{3}{|l|}{ male } & \multicolumn{2}{|c|}{ female } & \multicolumn{4}{|l|}{ total } \\
\hline & \multicolumn{3}{|l|}{$22(44 \%)$} & \multicolumn{2}{|c|}{$28(56 \%)$} & \multicolumn{4}{|c|}{$50(100 \%)$} \\
\hline age & \multicolumn{3}{|c|}{$39.1(\mathrm{sd}=12.6)$} & \multicolumn{2}{|c|}{$37.4(\mathrm{sd}=11.4)$} & \multicolumn{4}{|c|}{$38(\mathrm{sd}=11.8)$} \\
\hline \multirow[t]{2}{*}{ cognitive impairment } & $\mathrm{mci}$ & moci & sci & $\mathrm{pci}$ & $\mathrm{m}$ & \multicolumn{4}{|l|}{ total } \\
\hline & $23(46 \%)$ & $16(32 \%)$ & $\begin{array}{l}9 \\
(18 \%)\end{array}$ & $\begin{array}{l}2 \\
(4 \%)\end{array}$ & 0 & \multicolumn{4}{|c|}{$\begin{array}{l}50 \\
(100 \%)\end{array}$} \\
\hline \multirow[t]{2}{*}{ diagnoses } & FO & $\mathrm{F} 2$ & F3 & F4 & F6 & ADHD & Autism & ns & total \\
\hline & $\begin{array}{l}8 \\
(16 \%)\end{array}$ & $\begin{array}{l}12 \\
(24 \%)\end{array}$ & $21(42 \%)$ & $\begin{array}{l}5 \\
(10 \%)\end{array}$ & $\begin{array}{l}1 \\
(2 \%)\end{array}$ & $\begin{array}{l}3 \\
(6 \%)\end{array}$ & 0 & 0 & $\begin{array}{l}50 \\
(100 \%)\end{array}$ \\
\hline developmental level & fa & fs & fin & fid & $r$ & \multicolumn{4}{|l|}{ total } \\
\hline acoording SAED & $\begin{array}{l}4 \\
(8 \%)\end{array}$ & $\begin{array}{l}7 \\
(14 \%)\end{array}$ & $\begin{array}{l}10 \\
(20 \%)\end{array}$ & $\begin{array}{l}14 \\
(28 \%)\end{array}$ & $\begin{array}{l}15 \\
(30 \%)\end{array}$ & \multicolumn{4}{|c|}{50} \\
\hline
\end{tabular}


sd: standard deviation

mci: mild cognitive impairment; moci: moderate cognitive impairment; sci: severe cognitive impairment; pci: profound cognitive impairment; $\mathbf{m}$ : missing

ns: not specified

fa: first adaption; fs: first socialisation; fin: first individuation; fid: first identification; $r$ : reality awareness 
Table 3: Relationships between sex, age, cognitive impairment, psychiatric diagnoses, and developmental level

Sample 1: Team evaluation

\begin{tabular}{|c|c|c|c|c|}
\hline Variables & Statistical Method & $\begin{array}{l}\text { Correlation coefficient/ } \\
\text { Test Statistic }\end{array}$ & $p$ & $\mathrm{n}$ \\
\hline sex and age & Pearson correlation & $\rho=0.005$ & .95 & 175 \\
\hline $\begin{array}{l}\text { sex and cognitive } \\
\text { impairment }\end{array}$ & $\begin{array}{l}\text { Spearman } \\
\text { correlation }\end{array}$ & $\rho=-0.018$ & .81 & 169 \\
\hline $\begin{array}{l}\text { sex and socio-emotional } \\
\text { development (SAED) }\end{array}$ & & $\rho=0.083$ & .27 & 175 \\
\hline $\begin{array}{l}\text { age and socio-emotional } \\
\text { development (SAED) }\end{array}$ & & $\rho=-0.160$ & .034 & 175 \\
\hline $\begin{array}{l}\text { age and cognitive } \\
\text { impairment }\end{array}$ & & $\rho=-0.120$ & .12 & 169 \\
\hline age and diagnoses & Kruskal-Wallis-Test & $X^{2}(8)=6.133$ & .63 & 165 \\
\hline sex and diagnoses & Chi-Square-Test & $X^{2}(8)=21.847$ & .005 & 165 \\
\hline $\begin{array}{l}\text { cognitive impairment and } \\
\text { socio-emotional } \\
\text { development (SAED) }\end{array}$ & $\begin{array}{l}\text { Spearman } \\
\text { correlation }\end{array}$ & $\rho=0.516$ & $<.001$ & 169 \\
\hline
\end{tabular}

Sample 2: Intra- and Inter-rater-pairs-evaluation

\begin{tabular}{|l|l|l|l|l|}
\hline Variables & Statistical Method & $\begin{array}{l}\text { Correlation coefficient/ } \\
\text { Test Statistic }\end{array}$ & $\mathbf{p}$ & $\mathbf{n}$ \\
\hline sex and age & Pearson correlation & $\rho=-0.078$ & .592 & 50 \\
\hline $\begin{array}{lllll}\text { sex and cognitive } \\
\text { impairment }\end{array}$ & $\begin{array}{l}\text { Spearman } \\
\text { correlation }\end{array}$ & $\rho=0.057$ & .694 & 50 \\
\cline { 1 - 4 } $\begin{array}{l}\text { sex and socio-emotional } \\
\text { development (SAED) }\end{array}$ & & $\rho=-0.085$ & .558 & 50 \\
\cline { 3 - 6 } $\begin{array}{l}\text { age and socio-emotional } \\
\text { development (SAED) }\end{array}$ & & $\rho=-0.152$ & .292 & 50 \\
\cline { 3 - 5 } & & & & \\
\hline
\end{tabular}




\begin{tabular}{|l|l|l|l|l|}
\hline $\begin{array}{l}\text { age and cognitive } \\
\text { impairment }\end{array}$ & $\rho=-0.185$ & .198 & 50 \\
\hline age and diagnoses & Kruskal-Wallis-Test & $X^{2}(8)=0.715$ & .398 & 50 \\
\hline sex and diagnoses & Chi-Square-Test & $X^{2}(8)=3.212$ & .523 & 50 \\
\hline $\begin{array}{l}\text { cognitive impairment and } \\
\text { socio-emotional } \\
\text { development (SAED) }\end{array}$ & $\begin{array}{l}\text { Spearman } \\
\text { correlation }\end{array}$ & $\rho=0.668$ & $<.001$ & 50 \\
\hline
\end{tabular}


Table 4: Inter-Correlation-Matrix for the total score and the ten dimensions of the SAED

\begin{tabular}{|c|c|c|c|c|c|c|c|c|c|c|c|}
\hline & $\begin{array}{l}\text { SAED } \\
\text { total }\end{array}$ & 1 & 2 & 3 & 4 & 5 & 6 & 7 & 8 & 9 & 10 \\
\hline $\begin{array}{l}\text { SAED } \\
\text { total }\end{array}$ & 1. & 783 & ,822 & 798 & 671 & 699 & 754 & 793 & ,742 & 775 & ,766 \\
\hline 1 & . & 1. & 704 & 624 & ,544 & ,483 & ,586 & 667, & 601 & 604, & 589, \\
\hline 2 & . & . & 1. & 7466 & ,533 & ,590 & 686 & 696 & 688 & 731 & 654, \\
\hline 3 & . & . & . & 1. & ,512 & ,612 & ,704 & ,606 & 660 & ,693 & ,683 \\
\hline 4 & . & . & . & . & 1. & ,520 & ,423 & 606 & 517, & 547, & 556, \\
\hline 5 & . & . & . & . & & 1. & 699 & 562, & 699 & 687, & 556, \\
\hline 6 & . & . & . & . & . & . & 1- & ,642 & 596, & 765, & 599, \\
\hline 7 & . & . & . & . & . & . & . & 1. & 649, & 658, & 598, \\
\hline 8 & & . & . & 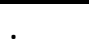 & & & . & . & 1. & 687, & 586, \\
\hline 9 & . & . & . & . & . & . & . & . & . & 1. & 679, \\
\hline 10 & & . & . & & & & . & & . & & 1. \\
\hline
\end{tabular}

Spearman's $\rho$

All correlations are significant $(p<.01)$

1: How he or she deals with his own body; 2: Interaction with caregivers; 3 : Experience of self; 4: Object permanency; 5: Anxiety; 6: Interaction with peers; 7: Handling with material objects; 8: Verbal communication; 9: Affect differentiation; 10: Aggression regulation 
Table 5: Intra- and inter-rater-reliability of the SAED (weighted Kappa-scores; $n=50$ )

\begin{tabular}{|l|l|l|}
\hline SAED dimensions & Intra-Rater-Reliability & Inter-Rater-Reliability \\
\hline SAED total & .71 & .56 \\
\hline 1. How he deals with his own body & .69 & .59 \\
\hline 2. Interaction with caregivers & .73 & .53 \\
\hline 3. Experience of self & .70 & .60 \\
\hline 4. Object permanency & .59 & .32 \\
\hline 5. Anxiety & .78 & .45 \\
\hline 6. Interaction with peers & .66 & .53 \\
\hline 7. Handling with material objects & .81 & .36 \\
\hline 8. Verbal communication & .72 & .66 \\
\hline 9. Affect differentiation & .60 & .55 \\
\hline 10. Aggression regulation & .56 & .49 \\
\hline
\end{tabular}

Weighted Kappa

All values are significant $(p<.001)$ 
Figure 1

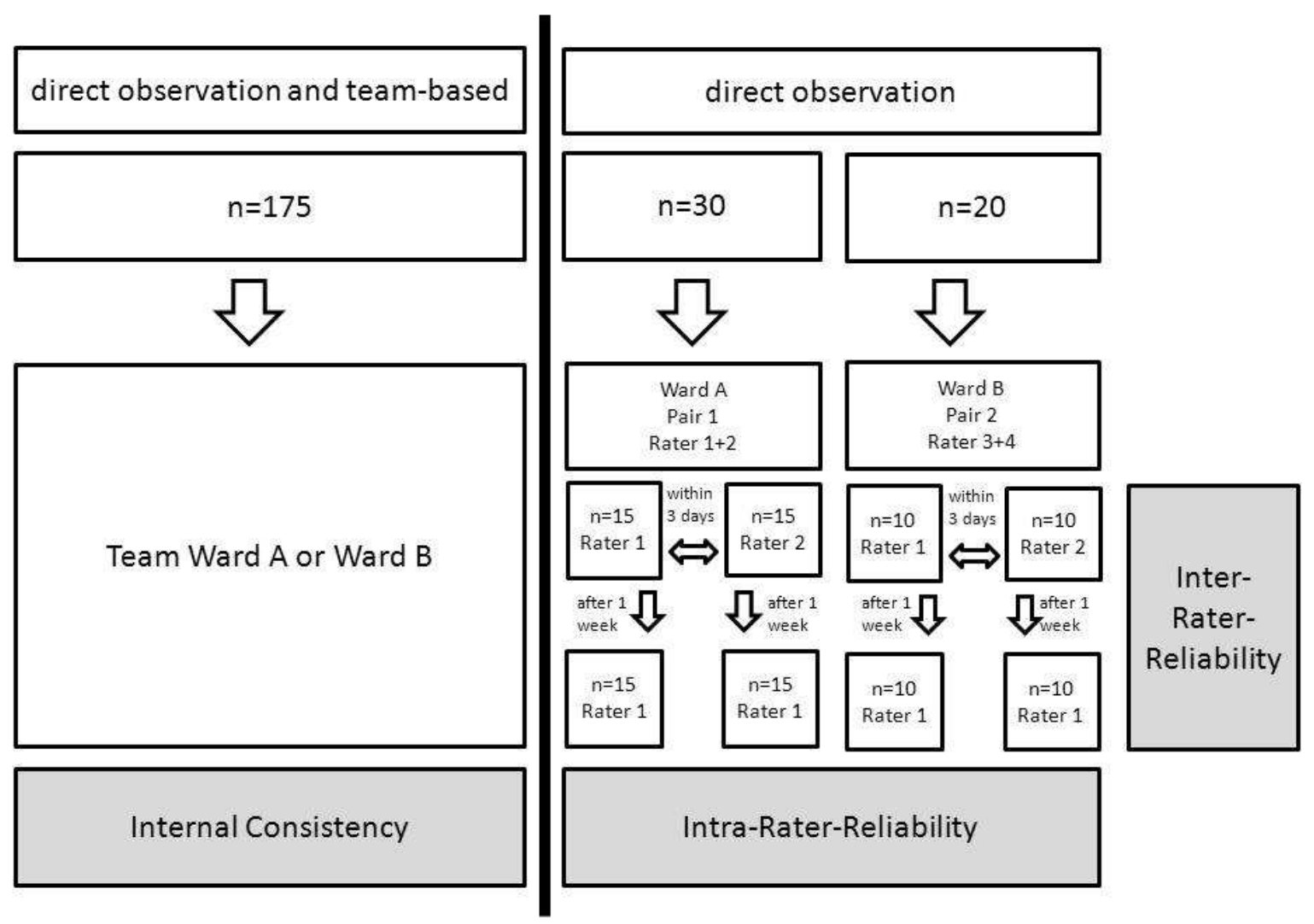

Figure 1: procedure of data acquisition 